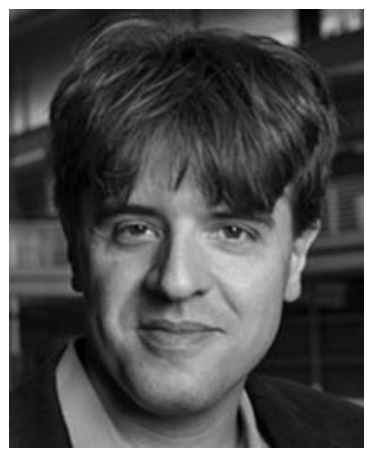

\title{
A Conversation with Karl Deisseroth
}

\author{
INTERVIEWER: JAN WITKOWSKI \\ Executive Director of the Banbury Center \\ at Cold Spring Harbor Laboratory
}

Karl Deisseroth is the D.H. Chen Professor of Bioengineering and of Psychiatry and Behavioral Sciences at Stanford University.

Jan Witkowski: You are speaking at this meeting about two topics, optogenetics and CLARITY.

Dr. Deisseroth: We've been developing optical technologies for exchanging information with the brain of experimental animals that are carrying out complex behaviors. Optogenetics is one of those. It's a way of using light to control well-defined sets of cells within neurocircuitry during behaviors, to turn them on, turn them off, and assess the causal impact on behavior. Social behavior is in many ways a high-level cognitive task, and it's difficult. It also carries risks. An organism has to be motivated to carry out a social interaction. We have some results on the optogenetic control of circuits in mice that turn up or down the tendency to engage in social interaction.

Jan Witkowski: What sort of social interactions are you looking at?

Dr. Deisseroth: A lot of great work in the past has been done on courtship but we're taking a slightly different tack. Same-sex mice of the same species have a natural willingness or desire to simply be in the same location as each other. If you give animals a choice of being alone or with a novel object of some interest or with another mouse of the same species and gender, they'll prefer to be with the mouse of the same species. There'll be active engagement and approach. It's an interesting built-in process. We're interested in what drives that, what turns that up, what turns that down. We quantify the amount of time the animals choose to spend engaged in this behavior.

Jan Witkowski: What's known about the neural circuits, neurons, or brain areas involved in this behavior?

Dr. Deisseroth: There are different aspects of social behavior. It is a challenge and it also requires motivation. These two aspects map on to certain neural circuits. The prefrontal cortex, which integrates much information and helps generate plans and move towards goals, is certainly involved. But deeper subcortical structures that involve recruitment of reward and motivation pathways are also involved.
Jan Witkowski: Do you think that by using optogenetics and manipulating particular neurons, you'll be able to drive the mice to particular types of behavior?

Dr. Deisseroth: That is a deep question. We're playing with patterns of activity. We're turning up or down certain kinds of behavior, so yes, the short answer is that mice can be modulated in the kinds of behavioral choices they carry out. But we don't want to just play with activity that we think is relevant, we'd also like to see what the animal normally uses. We have a new technique called fiber photometry which lets us collect information on what circuitry the animals normally use in the course of its social decisions and social choices. That's very powerful because then we can see what's normally present and try to mimic it in our experimental interventions.

Fiber photometry is a trick that uses an optical chopper to break the incoming signal at a very specific frequency. We have a detector to pick up signals coming out of the animal that's also tuned to detect signals at just that frequency. The advantage of this is that it lets us detect very small signals that otherwise would be buried in the noise, because only the signal we're interested in modulated at this frequency. So even in a mouse that's freely behaving in a well-lit room, we can pick up activity signals with fluorescent indicators of neural activity that are buried deep within the brain, and some of these neural circuits are involved in social behaviors.

Jan Witkowski: These are free roaming mice with implants to detect these signals?

Dr. Deisseroth: There's a single thin fiber optic that is able to implement either the optogenetic control or the fiber photometry detection of the signal. This is the key advantage: In both cases, it's the same system, same surgery, same location, same site, one thin optic fiber that both delivers the control and can pick up the activity signal. Then in the same animal, we can get both data streams.

Jan Witkowski: Do they use the same fluorescent compounds? 
Dr. Deisseroth: For the control, we use proteins encoded by microbial opsin genes that come from algae, from bacteria. They respond to light and open ion channels in the membrane. They themselves don't generate an optical signal but they use light to move ions across the membranes of cells that we're controlling. We pick up the signals and detect the native activity patterns using a different protein. These are genetically encoded reporters of ion flow. Two parallel sets of proteins that help us do the job.

Jan Witkowski: These are transgenic mice. How have you introduced the genes?

Dr. Deisseroth: In both cases, we've injected a virus that carries the gene encoding for these proteins. We take mice that could be transgenic but also can be wild-type mice that have no label.

Jan Witkowski: Eric Nestler has mice that are susceptible to depression. You can see that your system could be used to interrogate what's actually happening in the brains of these mice.

Dr. Deisseroth: Yes, Eric is quite interested in applying the fiber work to his model.

Jan Witkowski: What's the current state of CLARITY at the moment?

Dr. Deisseroth: With CLARITY, we are able to use a chemical engineering trick to make the brain transparent. It looks like it's gone but it's not, just all the light scattering has gone so you see through the brain. We do this by removing the lipids and removing the fats but before we do that, we make the brain robust by building in a hydrogel which keeps all the proteins and cells in place.

We published that about a year ago and the first papers using it are starting to come out. A nice study in spinal cord has just come out from another group. One thing we've been working on is trying to make it faster and easier to use, making the whole process and the data acquisition faster by orders of magnitude, combining CLARITY with light-sheet microscopy. We call this CLARITY-optimized light-sheet microscopy. It lets you collect volumes a 100 or a 1000 times faster than before.

Jan Witkowski: How long does it take to prepare a brain as you were doing 6 months or 9 months ago?

Dr. Deisseroth: For a mouse brain, the actual preparation process takes between a couple of days to a couple of weeks depending on how much you want to stain or label for. The whole process of making the brain transparent and creating a signal is a couple of weeks. What we really sped up is the imaging process. Whole-brain imaging now can be done in tens of minutes or hours, instead of days.

Jan Witkowski: This is imaging with what technique?

Dr. Deisseroth: It's a 100-year old concept called light sheet. With light sheet, you scan a plane of light through your tissue, instead of scanning a point as in confocal and two photon microscopy. These approaches give very nice high resolution but they are quite slow, and also have the disadvantage that you're imaging at a point but illuminating your whole sample which creates bleaching problems and degradation of your signal. With light sheet, you're only illuminating where you're imaging, so it's very efficient and fast. You're not destroying your signal in other parts of the tissue. It required some adaptation to make it well suited for these sorts of intact tissue preparations of the CLARITY-treated brain, or clarified brain as we say.

Jan Witkowski: What's the thickness of these sheets?

Dr. Deisseroth: Traditional resolution in that axis has been considered to be limited to the 10- to 20-micron range. That has to do with the thickness of the light sheet. This is something that can be improved upon with certain kinds of innovations. We can get now, even deep within the tissue, micron-level resolution. We can see fine processes, axons, and dendrites even deep in the middle of the mouse brain, so that's an exciting advance. Not only do we have the speed but we can maintain this high resolution.

Jan Witkowski: What one would like to do is get an insight into dynamics. Do you have a mouse that's been trained to do something or respond in some particular way whose brain you can compare with the brain of a control mouse? What sort of questions can you ask using this technique?

Dr. Deisseroth: What we've been working on is making sure you can do all of this in the same mouse. Not at the same time, but the same mouse at different times. This integration of data streams is a very powerful thing. You can now have a mouse that you've an optogenetic control experiment on. You've turned on or off different kinds of cells. You know that animal's behavior score. In that same animal you might even have done a fiber photometry experiment, or other kinds of imaging to see the native natural patterns of activity in that same mouse, during that same behavior. You can now take that same brain and put it through the CLARITY process. You can register or align the datasets you get at very different times and under different conditions. You can register the datasets and identify regions and cells during behavior. Here is their phenotype, here's their wiring. The goal is to move towards a more integrative understanding of the neural circuitry.

Jan Witkowski: How generally applicable is the clarification technique? Have people tried it with other tissues?

Dr. Deisseroth: There's been an explosion of interest. People have sent us pictures of clarified hearts, pancreata, even whole embryos. There are subtle tweaks to each preparation that are needed. For example, with the mouse brain, to speed up the processes, traditionally we've accelerated the clearance of the tissue by imposing an electric field. You can accelerate the clearance of these lipidcontaining micelles out of the tissue. What we're now finding is that for the brain you usually don't have to do this. You can do what we call passive clearing and it's fast enough and good enough. You don't even need the 
electrophoretic process, which has been a boon for a lot of people who didn't want to get the whole electrophoretic process going. But people are finding for other organs, like the heart, that the electrophoretic method is very important. You can't dispense with that. That has to do with tissue properties and there are different issues for every tissue.
The hard part about working with clarified tissue is representing it in the published page, because there's not really much to see. How do you show a picture of that? We've been trying different strategies, putting the brain over text, over grids that you can read through and so on. In the end people mostly care about the data and that's what we focus on presenting to them. 


\section{$\$_{\text {CSH }}^{\infty}$ Cold Spring Harbor Symposia SYMPOSIA On Quantitative Biology}

\section{A Conversation with Karl Deisseroth}

Cold Spring Harb Symp Quant Biol 2014 79: 266-268

Access the most recent version at doi:10.1101/sqb.2014.79.07

\section{License}

Email Alerting Receive free email alerts when new articles cite this article - sign up in Service the box at the top right corner of the article or click here. 